\title{
Conservation of the amino-terminal epitope of elongation factor Tu in eubacteria and archaea
}

\author{
Melanie Baensch, ${ }^{1}$ Ronald Frank ${ }^{2}$ and Jörg Köhl ${ }^{1}$
}

Author for correspondence: Jörg Köhl. Tel: +49511532 4340. Fax: +495115324366. e-mail: Koehl.Joerg@MH-Hannover.DE

1 Institute of Medical Microbiology, Medical School Hannover, 30623 Hannover, Germany

2 AG Molecular Recognition, GBF (Gesellschaft für Biotechnologische Forschung), Braunschweig, Germany

\begin{abstract}
An epitope of elongation factor Tu (EF-TU), which is found in organisms in both the bacterial and archaeal domains, was recently defined by mAb 900 . To localize the conserved epitope within the EF-Tu molecule and to determine its sequence, SPOTScan analysis of synthetic peptides, Western blot analysis of purified EF-Tu domains and site-directed mutagenesis studies were used. Analysis of mAb 900 binding to overlapping 15-mer peptides encompassing the complete sequence of EF-Tu of Escherichia coli was inconclusive, suggesting three distinct regions may be epitopes. Western blot analysis of EFTu domains 1-3 of Thermus thermophilus suggested that the epitope was located at the $\mathbf{N}$ terminus. This was confirmed by site-directed mutagenesis of EF-Tu domain 1 of Mycoplasma hominis. By C-terminal truncation of the Nterminal 15-mer peptide the epitope was mapped to EF-Tu residues 1-6. Replacement of each of the residues in the epitope peptide demonstrated that only positions 5 and 6 were indispensable for antibody binding. These data provide evidence that the highly conserved epitope recognized by mAb 900 in the bacterial and archaeal domains is located at the very end of the $\mathbf{N}$ terminus of the EF-Tu molecule.
\end{abstract}

Keywords: archaeal domain, bacterial domain, elongation factor Tu, EF-Tu, epitope mapping

\section{INTRODUCTION}

During translation, elongation factor $\mathrm{Tu}(\mathrm{EF}-\mathrm{Tu}\rangle$ promotes the GTP-dependent binding of aminoacyltRNA to the ribosome (Miller \& Weissbach, 1977). Due to this essential role in protein biosynthesis, EF-Tu has been extensively investigated structurally and functionally (Berchtold et al., 1993; Nissen et al., 1995; Weijland \& Parmeggiani, 1994). In addition, tuf genes have been widely used as a tool to determine phylogenetic relationships (Filer \& Furano, 1980, 1981a, b; Sela et al., 1989; Wenzig \& Schleifer, 1989; Ludwig et al., 1990; Baldauf et al., 1996).

Our laboratory recently characterized mAb 900 , which recognized an epitope of EF-Tu in organisms from both the bacterial and archaeal domains but not in those from the eukaryote domain (Weber et al., 1995). However, although mAb 900 recognized more than 90 different species belonging to either the bacterial or archaeal domains, some species within a given phylum were not

Abbreviation: EF-Tu, elongation factor Tu. recognized while other, more distantly related species from other phyla were recognized.

To understand the basis of the patterns of reactivity of mAb 900 we first mapped the epitope of mAb 900 using SPOTScan analysis, EF-Tu domain analysis, and sitedirected mutagenesis of the EF-Tu domain of Mycoplasma hominis. We then used this sequence information to analyse EF-Tu sequences from the SWISS-PROT database.

\section{METHODS}

Micro-organisms. M. hominis (NCTC 10111), Mycoplasma pneumoniae (NCTC 10119), Mycoplasma gallisepticum (NCTC 10115) and Mycoplasma genitalium (NCTC 10120) were obtained from the National Collection of Type Cultures, London, UK). The strains were grown at $37^{\circ} \mathrm{C}$ in $200 \mathrm{ml}$ cellculture flasks (Nunc) containing $100 \mathrm{ml}$ culture medium as described previously (Schmitt et al., 1988). Deinococcus radiodurans 'sark', Deinococcus radiophilus and Deinobacter grandis were kindly provided by R. G. E. Murray (Department of Microbiology and Immunology, University of Western Ontario, London, Canada). Archaeoglobus fulgidus, Pyrobaculum aerophilum, Methanococcus igneus, Methanopyrus 
kandleri, Methanothermus fervidus and Pyrodictium abyssii were kindly provided and were tested for reactivity with $\mathrm{mAb}$ 900 in Western blots by R. Wirth (Institut für Mikrobiologie, Universität Regensburg, Germany). All other species listed in Table 1 were obtained as described previously (Weber et al., 1995).

EF-Tu domains of Thermus thermophilus. The EF-Tu molecule consists of three distinct domains according to the X-ray crystallographic model: domain 1 (residues 1-200), domain 2 (residues 201-299) and domain 3 (residues 300-393) (Kjeldgaard \& Nyborg, 1992). The EF-Tu domains of $T$. thermopbilus were purified using anion-exchange chromatography on Q-Sepharose Fast Flow (Pharmacia) and gel filtration through Sephacryl S-200 (Pharmacia) as described by Nock et al. (1995). Purified domains 1, 1 and 2, and 3 were subjected to SDS-PAGE (12.5\% polyacrylamide) and were either stained with silver nitrate or used for Western blot analysis with $\mathrm{mAb} 900$. The purified EF-Tu domains of $T$. thermophilus were kindly provided by S. Nock and M. Sprinzl (Lehrstuhl für Biochemie, Universität Bayreuth, Germany).

Peptide synthesis. Peptides were synthesized as arrays of $\mathrm{N}$ terminally acylated and C-terminally covalently immobilized products on cellulose sheets derivatized with $\beta$ Ala- $\beta$ Ala dipeptide anchors by the spot synthesis technique as described by Frank (1992) and Frank \& Overwin (1996) using a model ASP 222 spotting robot (ABIMED Analysen-Technik). Binding of $\mathrm{mAb} 900$ to peptide spots was assayed as described by Frank \& Overwin (1996) using a goat-anti-mouse secondary antibody conjugate with alkaline phosphatase. Peptide arrays included (i) overlapping pentadecapeptides with an offset of 2 or 5 amino acid residues resulting in either 77 (5 residue offset) or 190 ( 2 residue offset) different peptides, spanning the whole 393 amino acid sequence of EF-Tu (SPOTScan analysis), (ii) overlapping peptides of stepwise reduced length with an offset of only 1 amino acid residue spanning the N-terminal 15 residues of EF-Tu (SPOTSize analysis), and (iii) systematic single amino acid replacement analogues (SPOTSalogue analysis) of the minimal hexapeptide epitope.

SDSPAGE and immunoblotting. SDS-PAGE was performed according to the method of Laemmli (1970). After addition of the sample buffer, the sample solution was boiled for $5 \mathrm{~min}$ and proteins separated by SDS-PAGE through $12.5 \%$ polyacrylamide gels. Subsequently, proteins were stained with silver nitrate. For immunoblotting, the proteins were electrotransferred to a nitrocellulose membrane $(0.45 \mu \mathrm{m}$ pore size; Schleicher \& Schüll) and then incubated for $2 \mathrm{~h}$ with $\mathrm{mAb} 900$ at room temperature. Binding was detected by incubation of the membrane with biotinylated anti-mouse immunoglobulin antibody (Amersham), diluted $1: 1000$ in PBS $(0.01 \mathrm{M}$ $\left.\mathrm{NaH}_{2} \mathrm{PO}_{4} / \mathrm{Na}_{2} \mathrm{HPO}_{4}\right) / 1 \%$ BSA, for $1 \mathrm{~h}$ at room temperature, followed by incubation with avidin horseradish peroxidase (Sigma) for $30 \mathrm{~min}$ at room temperature. The Western blot was developed using 4-chloro-1-naphthol (Sigma) as substrate.

Release of EF-Tu from deinococci. Deinococci were grown in Luria-Bertani (LB) medium until the $\mathrm{OD}_{600}$ of the culture reached 100. Bacteria were harvested by centrifugation and resuspended in $100 \mu \mathrm{l} 10 \mathrm{mM}$ PBS, $\mathrm{pH} 7 \cdot 5$. Bacterial cell walls were disrupted using glass beads as described by Weber $e t$ al. (1995). The bacterial lysates $(15 \mu \mathrm{l})$ were either directly added to an equal amount of SDS sample buffer and used for SDSPAGE or stored at $-70^{\circ} \mathrm{C}$ until use.

Site-directed mutagenesis and expression of EF-Tu domain 1 of $M$. hominis. Mutagenesis of the $\mathrm{N}$ terminus of EF-Tu domain 1 of $M$. hominis was performed by PCR. Oligo- nucleotides JK 88 (5' GTC CTC GCA ACT GCG GCC CAG CCG GCC ATG GCC AAA GAA AAA TTT GAA CGT TCA AAA CC $\left.3^{\prime}\right)\left(5^{\prime}\right.$ primer) and JK 91 (5' G AGA GAG AGA AAG CTT TTA TTA GAT GTA TGT ATC AAC AGC C $\left.3^{\prime}\right)\left(3^{\prime}\right.$ primer) were used to amplify a $609 \mathrm{bp}$ fragment encoding the mutated EF-Tu domain 1. Primer JK 88 introduced three amino acid replacements at positions 3,4 and 6: Glu for Leu, Lys for Asp and Glu for Asp, respectively. Plasmid pMHEL2 (kindly provided by E. Lüneberg, Institut für Hygiene und Mikrobiologie, Würzburg, Germany), which contains the whole gene encoding the EF-Tu sequence of $M$. hominis (Lüneberg et al., 1991), served as template. The amplified EFTu fragment was digested with $\mathrm{NcoI}$ and HindIII and cloned into the expression vector pTrc99A (Pharmacia Biotech) using standard protocols (Sambrook et al., 1989). DNA sequencing confirmed the expected amino acid sequence of the mutated fragment. Subsequently, the plasmid harbouring the mutated EF-Tu domain 1 sequence of $M$. hominis (pTUMB 1) was used to transform electroporation-competent TG1 cells (Stratagene). In addition, TG1 cells were transformed with pTrc99A without an insert. For expression, TG1 cells were grown overnight in $2 \times$ TY broth $(0.1 \%$ tryptone, $0.05 \%$ yeast extract, $0.8 \% \mathrm{NaCl}$ be added on proof) containing $100 \mu \mathrm{g}$ ampicillin $\mathrm{ml}^{-1}(2 \times \mathrm{TY}$-AMP). The next day, $0.5 \mathrm{ml}$ of the overnight culture was added to $4.5 \mathrm{ml}$ fresh $2 \times$ TY-AMP broth containing $1 \mathrm{mM}$ IPTG. Bacteria were grown for $3 \mathrm{~h}$ at $37^{\circ} \mathrm{C}$. The culture was then centrifuged at $5000 \mathrm{~g}$ for $10 \mathrm{~min}$. The pelleted cells were resuspended in SDS sample buffer and boiled for $5 \mathrm{~min}$ before separation of the proteins by SDSPAGE through a $15 \%$ polyacrylamide gel.

Amino acid alignment. This was performed using the PC GENE program (IntelliGenetics) and the SWISS-PROT protein sequence database.

\section{RESULTS AND DISCUSSION}

\section{Binding sites of mAb 900 identified by SPOTScan and domain analysis}

MAb 900 recognized EF-Tu in Western blots, indicating that it detects a continuous epitope of the EF-Tu molecule. As shown in Fig. 1, SPOTScan analysis showed that mAb 900 bound to three different regions within the EF-Tu molecule. The strongest signal was obtained with the very $\mathrm{N}$-terminal peptide SKEKFERTKPHVNVG. However, the adjacent peptides, lacking either the first two or five $\mathrm{N}$-terminal residues were not detected. This result strongly suggested that the first two $\mathrm{N}$-terminal residues were essential for $\mathrm{mAb} 900$ binding to EF-Tu.

The second region detected comprised two peptides. The consensus motif of these peptides was GAARAFDQID (amino acid positions 41-50; Fig. 1). This region is part of the effector region of EF-Tu, which interacts with the ribosome (Berchtold et al., 1993). In T. thermophilus it has been demonstrated that the effector region can be divided into two segments, positions 41-49 and positions 54-60, with the latter region wellconserved between species. In contrast, positions 41-49 are the most variable between species. Thus, the peptide sequence ARAFDQIDN may be a distinct, alternative epitope ligand structure recognized by $\mathrm{mAb} 900$, but it is unlikely to be the highly conserved epitope detected by $\mathrm{mAb} 900$ throughout the bacterial superkingdom. 


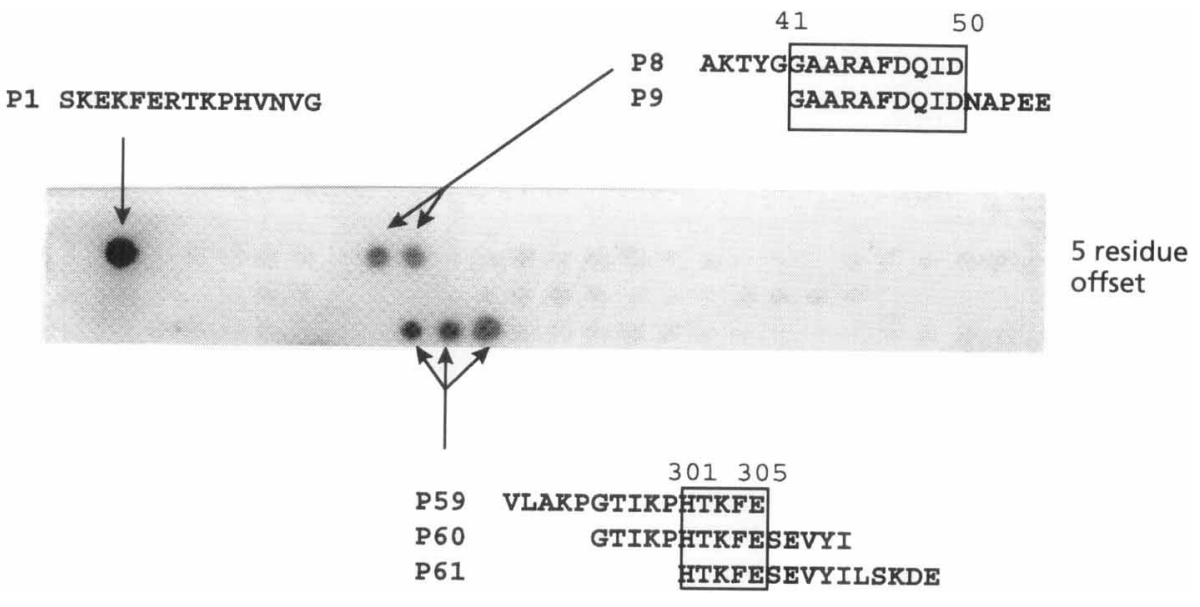

Fig. 1. SPOTScan analysis of EF-Tu of $E$. coli. Fifteen-mer peptides with an offset of five amino acid residues (P1-P70), which span the whole sequence of EF-Tu of E. coli, were spotted on a cellulose sheet. The consensus motifs of peptides P8 and P9 and of peptides P59-P61, which were recognized by mAb 900, are indicated by boxes.

Table 1. Comparison of the amino-terminal sequence of bacterial EF-Tu molecules and their reaction with mAb 900

\begin{tabular}{|c|c|c|c|c|}
\hline Bacterial group & Species & $\begin{array}{c}\text { EF-Tu } \\
\text { sequence } \\
\text { (amino acid } \\
\text { positions 1-6) }\end{array}$ & $\begin{array}{c}\text { mAb } 900 \\
\text { reaction in } \\
\text { Western } \\
\text { blot }^{*}\end{array}$ & $\begin{array}{c}\text { SWISS- } \\
\text { PROT } \\
\text { accession } \\
\text { number }\end{array}$ \\
\hline $\begin{array}{l}\text { Cytophaga-Bacteroides- } \\
\text { Flavobacterium group }\end{array}$ & Bacteroides fragilis & A K E K F E & + & P33165 \\
\hline Chlamydiae & Chlamydia trachomatis & S K E T F Q & - & P26622 \\
\hline Gram-positive, low $\mathrm{G}+\mathrm{C}$ & $\begin{array}{l}\text { Mycoplasma gallisepticum } \\
\text { Mycoplasma hominis } \\
\text { Mycoplasma pneumoniae } \\
\text { Mycoplasma genitalium } \\
\text { Streptococcus oralis } \\
\text { Bacillus subtilis }\end{array}$ & $\begin{array}{l}\text { A K E R D } \\
\text { A K L D F D } \\
\text { A REKF D } \\
\text { A R E K D } \\
\text { AKEKY D } \\
\text { AKEKFD }\end{array}$ & $\begin{array}{l}- \\
- \\
- \\
- \\
+ \\
+\end{array}$ & $\begin{array}{l}\text { P18906 } \\
\text { P22679 } \\
\text { P23568 } \\
\text { P13927 } \\
\text { P33170 } \\
\text { P33166 }\end{array}$ \\
\hline Gram-positive, high $\mathrm{G}+\mathrm{C}$ & Mycobacterium tuberculosis & A K A K F Q & \pm & P31501 \\
\hline Proteobacteria $\gamma$-subdivision & $\begin{array}{l}\text { Pseudomonas aeruginosa } \\
\text { Escherichia coli }\end{array}$ & $\begin{array}{l}\text { A K A K F E } \\
\text { S K E K F E }\end{array}$ & $\begin{array}{l}+ \\
+\end{array}$ & $\begin{array}{l}\text { P09591 } \\
\text { P02990 }\end{array}$ \\
\hline Proteobacteria $\beta$-subdivision & Burkbolderia cepacia & A K G K F E & + & P33167 \\
\hline \multirow[t]{4}{*}{ Deinococci and relatives } & $\begin{array}{l}\text { Thermus } \\
\text { thermophilus }\end{array}$ & A K G E F V & - & P07157 \\
\hline & Deinococcus grandis & Not known & + & Not known \\
\hline & $\begin{array}{l}\text { Deinococcus } \\
\text { radiophilus }\end{array}$ & Not known & + & Not known \\
\hline & $\begin{array}{l}\text { Deinococcus } \\
\text { radiodurans }\end{array}$ & Not known & + & Not known \\
\hline
\end{tabular}

+ , Strong positive reaction; \pm , weak positive reaction; - , negative reaction.

At the border between domain 2 (positions 201-299) and 3 (positions 300-393) of EF-Tu, mAb 900 bound to three different peptides located at positions 291-315. The consensus motif of these peptides comprised positions
301-305 (HTKFE). As this motif is highly conserved within the bacterial domain it could, in principle, serve as the epitope of $\mathrm{mAb} 900$. It is noteworthy that the last three amino acids (KFE) of this consensus motif perfectly 


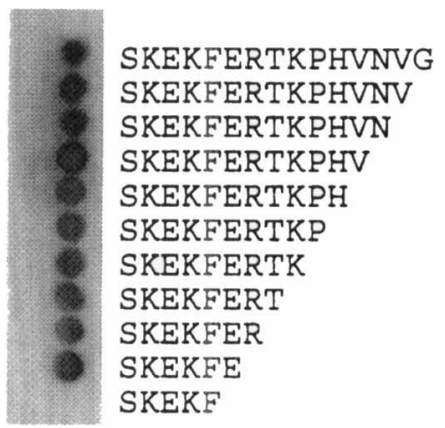

Fig. 2. SPOTSize analysis of the epitope of mAb 900 . The $\mathrm{N}$ terminal peptide SKEKFERTKPHVNVG was C-terminally truncated by stepwise deletion of one amino acid down to the four residue peptide. The last positive signal was obtained from the hexapeptide SKEKFE.

match the N-terminal positions $4-6$ of the EF-Tu molecule of Escherichia coli.

To determine whether amino acids $1-15$, amino acids 301-305 or both regions were the epitope of $\mathrm{mAb} 900$, we performed Western blot analysis of the three domains of EF-Tu of T. thermophilus. Alignment of the EF-Tu sequences of $T$. thermophilus and E. coli revealed that four of the six $\mathrm{N}$-terminal amino acids were different (i.e. positions 1, 3, 4 and 6; Table 1), and in addition the motif HTKFE was found in E. coli and EF-Tu of $T$. thermophilus (at positions 313-317). To test which sequence was recognized by mAb 900, EF-Tu domain 1 (positions 1-211), domains 1 and 2 (positions 1-311) or domain 3 (positions 312-405) were tested for reactivity with $\mathrm{mAb} 900$. None of the domains were detected by $\mathrm{mAb} 900$ in Western blot (data not shown) raising the question of why sequence HTKFE is recognized in SPOTScan analysis but not within the environment of domain 3 of $T$. thermophilus. It is conceivable that the HTKFE sequence, presented within the peptide, is accessible to $\mathrm{mAb} 900$ whereas it is not within the conformation of intact domain 3 . In addition, the different adjoining residues in E. coli or T. thermophilus, either $\mathrm{N}$ - or $\mathrm{C}$-terminal to HTKFE may influence the binding of the $\mathrm{mAb}$.

Taken together, the results of the SPOTScan analysis and the Western blot analysis strongly suggested that the $\mathrm{N}$ terminus of the EF-Tu molecule was the highly conserved sequence recognized by mAb 900 within the bacterial and archaeal domains (Weber et al., 1995).

\section{Definition of the binding epitope of mAb 900 using SPOTSize and SPOTSalogue analysis}

To determine the epitope boundaries of $\mathrm{mAb} 900$, we performed SPOTSize analysis. To localize the C-terminal boundary of the epitope within the $\mathrm{N}$-terminal 15 mer peptide, we successively truncated the peptide Cterminally to the tetramer SKEK. The shortest peptide detected by $\mathrm{mAb} 900$ was the hexamer SKEKFE (Fig. 2). The previous SPOTScan analysis had revealed that $\mathrm{N}$ -

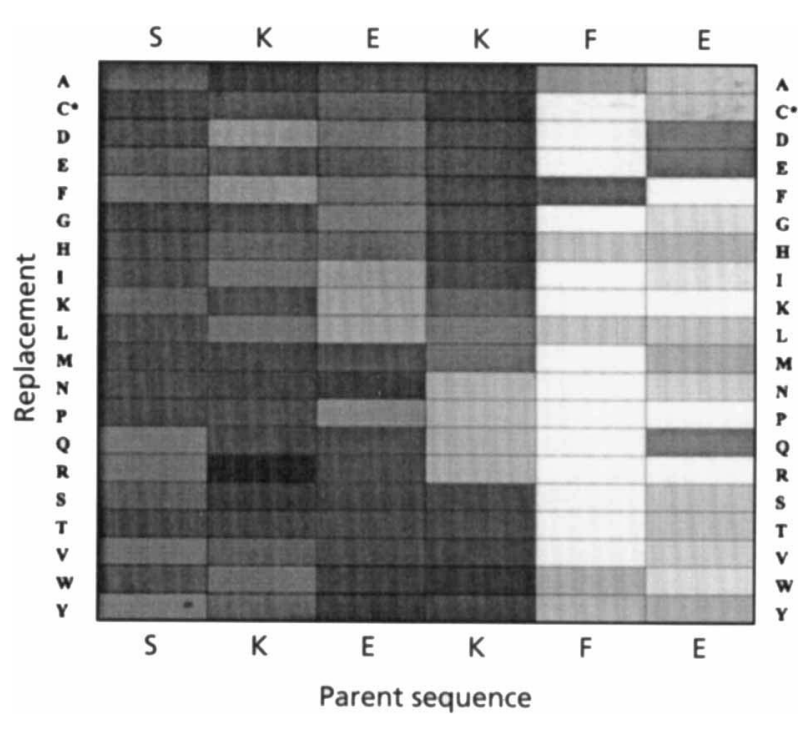

Fig. 3. Replacement analysis of the epitope of mAb 900. Every position of the parent sequence SKEKFE was replaced by one of the other naturally occurring 19 amino acids. Dark boxes denote a positive reaction with mAb 900 . White boxes indicate that this particular replacement resulted in abrogation of mAb 900 binding. $\mathrm{C}^{*}$, cysteine residue in which the $\mathrm{SH}$ group is protected by an acetamidomethyl-group.

terminal truncation of two residues completely abrogated $\mathrm{mAb} 900$ binding. To evaluate whether the full length of six amino acids was indispensable for antibody binding, the N-terminal serine was deleted and found to reduce binding (data not shown).

It is well-known that within a particular epitope not all residues bind with equivalent affinity to an antibody (Appel et al., 1990). To determine the key residues within the EF-Tu epitope, replacement analysis was performed using the SPOTSalogue technique. Within the peptide SKEKFE, every position was replaced by all other 19 naturally occurring amino acids (Fig. 3). This analysis demonstrated that both the $\mathrm{C}$-terminal residues, phenylalanine and glutamic acid, were indispensable for $\mathrm{mAb} 900$ binding. Only conservative replacements (Trp or Tyr for $\mathrm{Phe}^{5}$ or Asp for $\mathrm{Glu}^{6}$ ) were tolerated at these positions, whereas residues in positions $1-4$ could be substituted by nearly every other amino acid when single amino acid replacements were performed.

\section{Site-directed mutagenesis of EF-Tu domain 1 of $\boldsymbol{M}$. hominis}

EF-Tu of $M$. hominis is not recognized by $\mathrm{mAb} 900$ (Weber et al., 1995). The $\mathrm{N}$-terminal sequences of $E$. coli and $M$. hominis differ at four positions, 1, 3, 4 and 6 . To evaluate whether the $\mathrm{N}$-terminal $E$. coli sequence SKEKFE alone was sufficient to change the EF-Tu 


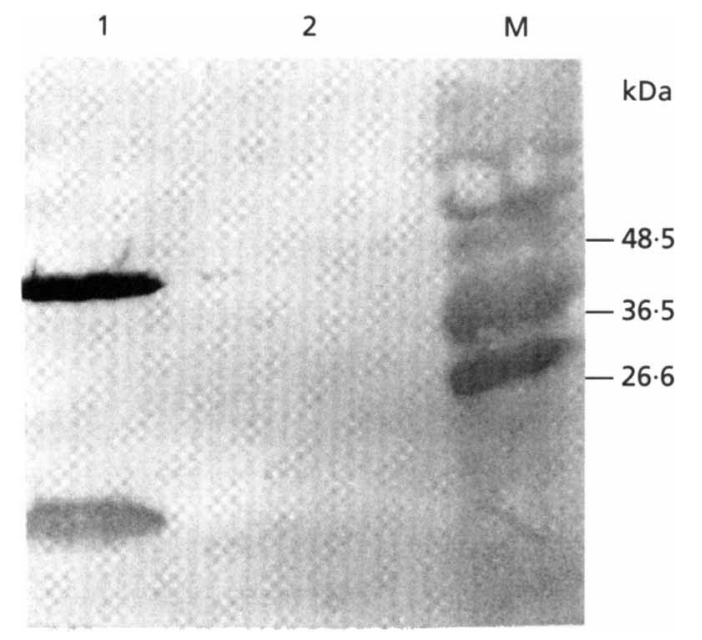

Fig. 4. Site-directed mutagenesis of EF-Tu domain 1 of $M$. hominis. Western blot of the mutated domain 1 expressed in $E$. coli (in lane 1, the strong band at $43 \mathrm{kDa}$ is due to the binding of mAb 900 to EF-Tu of E. coli). Only the band at $43 \mathrm{kDa}$ was detectable in bacteria transformed with the pTrc99a vector without an EF-Tu domain 1 insert (data not shown). As a control, a cell lysate of $M$. hominis was separated in lane 2. $M$, prestained markers (Sigma).

molecule of $M$. hominis to one recognized by $\mathrm{mAb} 900$, we performed site-directed mutagenesis of EF-Tu domain 1 of M. hominis. Amino acids at positions 3, 4 and 6 were replaced by those of $E$. coli. As alanine occurs in position 1 of the epitope recognized by $\mathrm{mAb} 900$ in many species (e.g. Bacteroides fragilis or Pseudomonas aeruginosa, see Table 1), it was not modified. The mutated domain 1 of $M$. hominis was recognized by mAb 900 (Fig. 4) indicating that the $\mathrm{N}$-terminal sequence SKEKFE was the epitope of $\mathrm{mAb} 900$ and confirming the data obtained by the SPOTSalogue analysis.

\section{Distribution of the epitope within the bacterial and archaeal domains}

Comparison of the epitope sequences of different species listed in the SWISS-PROT database revealed that positions $1,2,4,5$ and 6 were highly conserved. The most important residues for $\mathrm{mAb} 900$ binding, i.e. phenylalanine at position 5 or glutamic/aspartic acid at position 6 , occur in $91 \%$ and $71 \%$ of species, respectively. At positions 2 and $4,91 \%$ and $66 \%$ of residues are arginine/lysine and lysine, respectively. However, serine at position 1 is found only in about $13 \%$ of species. In fact, most often ( $80 \%$ of species) the residue in this position is alanine, which obviously does not inhibit mAb 900 binding (Fig. 3). Glutamic acid at position 3 is found only in about $30 \%$ of species. It is replaced by several other amino acids, most commonly by alanine or glycine. None of these replacements changed the binding properties of mAb 900 (Fig. 3; Table 1).

In a previous study we found that $\mathrm{mAb} 900$ does not recognize some closely related species within a given phylum (Weber et al., 1995). For example, 12 different species belonging to the phylum of Gram-positive bacteria with a low $\mathrm{G}+\mathrm{C}$ content were recognized by mAb 900, but Mycoplasma spp. were not. In comparison to the EF-Tu sequence of E. coli, four amino acid replacements at positions $1,3,4$ and 6 occur in the EFTu molecule of $M$. hominis. The failure of $\mathrm{mAb} 900$ to bind to EF-Tu of $M$. hominis can be attributed to the replacements at conserved positions 4 and 6 . A single amino acid replacement of Asp for Lys ${ }^{4}$ or Asp for $\mathrm{Glu}^{6}$ does not abrogate $\mathrm{mAb} 900$ binding, as has been demonstrated with SPOTSalogue analysis. However, the simultaneous replacement of both positions is deleterious. In the other Mycoplasma spp. tested, $\mathrm{Lys}^{2}$ is replaced by Arg and Glu ${ }^{6}$ by Asp, again demonstrating that the simultaneous replacement of two positions, one of which is the key residue $\mathrm{Glu}^{6}$, is detrimental for $\mathrm{mAb}$ 900 binding.

Within the Planctomyces-Chlamydia group, Chlamydia trachomatis was not recognized by mAb 900. As described for M. hominis, amino acid replacements occur at two different positions, one of which is the key residue Glu ${ }^{6}$ (Table 1 ).

In a previous report from our group (Weber et al., 1995), Deinococcus spp. and their close relatives were not tested for reactivity with mAb 900 by Western blotting. Here, we tested $D$. grandis, D. radiophilus and $D$. radiodurans and found all species to be recognized by mAb 900 (Table 1). Unfortunately, no EF-Tu sequences have yet been published from these bacteria.

Currently two EF-Tu sequences of archaea are available, i.e. those of Methanococcus vannielii and Haloarcula marismortui. The latter species was detected in Western blots by mAb 900 (Weber et al., 1995). However, neither the epitope sequence SKEKFE nor the other sequences detected by the SPOTScan analysis can be found within these EF-Tu sequences. However, at positions 47-53 of archaeal EF-Tu the sequence KGKGGFE is located, and this may mimic the SKEKFE epitope and thus serve as a binding domain for $\mathrm{mAb} 900$. This view is supported by the fact that the KGK motif also occurs in Burkholderia cepacia, an EF-Tu sequence which is detected by $\mathrm{mAb}$ 900 (Table 1). The glycine residues allow for a free rotation so that the key residues Phe and Glu may come in close contact with the KGK sequence, which allows them to fit into the antigen-binding site of mAb 900 .

When we performed a similarity scan, we found a perfect match of the KEKFE sub-sequence to the alphasubunit of methyl-coenzyme $M$ reductase of $M$. vannielii at the $\mathrm{N}$ terminus of the molecule. The molecular mass of this protein is $61 \mathrm{kDa}$. Although we did not test $M$. vannielii for reactivity with $\mathrm{mAb} 900$, this protein may also occur in other Euryarchaeota. The cross-reactivity to this protein could explain why mAb 900 stained a band of $60-80 \mathrm{kDa}$ but not of $45 \mathrm{kDa}$ in Western blots performed with different archaea (Weber et al., 1995).

In addition to the hitherto tested archaea, six species from the 'hyperthermophilic' archaea, Archaeoglobus 
fulgidus, Pyrobaculum aeropbilum, Methanococcus igneus, Methanopyrus kandleri, Methanothermus fervidus and Pyrodictium abyssii, were investigated. Of these, A. fulgidus (two bands at $45 \mathrm{kDa}$ and $70 \mathrm{kDa}$ ) and $P$. aerophilum (two bands at approx. $60 \mathrm{kDa}$ ) were detected by $\mathrm{mAb} 900$ (data not shown). The fact that $P$. aerophilum belongs to the order Thermoproteales within the crenarchaeotal kingdom suggests that the epitope of $\mathrm{mAb} 900$ is even present in this kingdom.

In summary, we mapped the epitope of $\mathrm{mAb} 900$ to the $\mathrm{N}$-terminal EF-Tu residues SKEKFE, a sequence which is highly conserved in the bacterial domain. Using the SPOTSalogue technique, the key residues $\mathrm{Phe}^{5}$ and $\mathrm{Glu}^{6}$ were identified. This information allowed us to address the failure of mAb 900 to recognize some closely related species within a given phylum. At the moment, we cannot be certain whether the sequence occurs in the archaeal elongation factor or whether the positive staining in Western blots is due to cross-reaction with other proteins.

\section{ACKNOWLEDGEMENTS}

We thank D. Bitter-Suermann for his continuous support and helpful discussions. The expert technical assistance in peptide synthesis by $\mathrm{A}$. Tiepold is gratefully acknowledged. This study was supported by EC project BIOT CT-910294 (participant 03) from the European Community.

\section{REFERENCES}

Appel, J. R., Pinilla, C., Niman, H. \& Houghten, R. (1990). Elucidation of discontinuous linear determinants in peptides. J Immunol 144, 976-983.

Baldauf, S. L., Palmer, J. D. \& Doolittle, W. F. (1996). The root of the universal tree and the origin of eukaryotes based on elongation factor phylogeny. Proc Natl Acad Sci USA 93, 7749-7754.

Berchtold, H., Reshetnikova, L., Reiser, C. O. A., Schirmer, N. K., Sprinzl, M. \& Hilgenfeld, R. (1993). Crystal structure of active elongation factor $\mathrm{Tu}$ reveals major domain rearrangements. Nature 365, 126-132.

Filer, D. \& Furano, A. V. (1980). Portions of the gene encoding elongation factor $\mathrm{Tu}$ are highly conserved. $J$ Biol Chem 255, 728-734.

Filer, D. \& Furano, A. V. (1981a). The conservation of DNA sequences over very long periods of evolutionary time. Eur $J$ Biochem 120, 67-77.

Filer, D. \& Furano, A. V. (1981b). Duplication of the tuf gene, which encodes peptide chain elongation factor $\mathrm{Tu}$, is widespread in gram-negative bacteria. J Bacteriol 148, 1006-1011.

Frank, R. (1992). Spot-Synthesis: an easy technique for the positionally addressable, parallel chemical synthesis on a membrane support. Tetrahedron 48, 9217-9232.
Frank, R. \& Overwin, H. (1996). SPOT Synthesis: epitope analysis with arrays of synthetic peptides prepared on cellulose membranes. In Methods in Molecular Biology, vol. 66, Epitope Mapping Protocols, pp. 149-169. Edited by G. E. Morris. Totowa: Humana Press.

Kjeldgaard, M. \& Nyborg, J. (1992). Refined structure of elongation factor EF-Tu from Escherichia coli. J Mol Biol 223, 721-742.

Laemmli, U. K. (1970). Cleavage of structural proteins during the assembly of the head of bacteriophage T4. Nature 227, 680-685.

Ludwig, W., Weizenegger, M., Betzl, D., Leidel, E., Lenz, T., Ludvigsen, A., Möllenhoff, D., Wenzig, P. \& Schleiffer, K.-H. (1990). Complete nucleotide sequences of seven eubacterial genes coding for the elongation factor $\mathrm{Tu}$ : structural and phylogenetic evaluations. Arch Microbiol 153, 241-247.

Lüneberg, E., Kamla, V., Hadding, U. \& Frosch, M. (1991). Sequence and expression in Escherichia coli of a Mycoplasma hominis gene encoding elongation factor Tu. Gene 102, 123-127.

Miller, D. L. \& Weissbach, H. (1977). Factors involved in the transfer of aminoacyl-tRNA to the ribosome. In Molecular Mechanisms of Protein Biosynthesis, pp. 323-374. Edited by $\mathrm{H}$. Weissbach \& S. Pestka. New York: Academic Press

Nissen, P., Kjeldgard, M., Thirup, S., Polekhina, G., Reshetnikova, L., Clark, B. F. C. \& Nyborg, J. (1995). Crystal structure of the ternary complex of Phe-tRNAPhe, EF-Tu, and a GTP analog. Science 270, 1464-1472.

Nock, S., Grillenbeck, N., Ahmadian, M. R., Ribeiro, S., Kreutzer, R. \& Sprinzl, M. (1995). Properties of isolated domains of the elongation factor $\mathrm{Tu}$ from Thermus thermophilus HB 8. Eur J Biochem 234, 132-139.

Sambrook, J., Fritsch, E. F. \& Maniatis, T. (1989). Molecular Cloning: a Laboratory Manual, 2nd edn. Cold Spring Harbor, NY: Cold Spring Harbor Laboratory.

Schmitt, K., Däubener, W., Bitter-Suermann, D. \& Hadding, U. (1988). A safe and efficient method for elimination of cell mycoplasmas using ciprofloxacin. J Immunol Methods 109 , $17-25$.

Sela, S., Yogev, D., Razin, S. \& Bercovier, H. (1989). Duplication of the tuf gene: a new insight into the phylogeny of eubacteria. $J$ Bacteriol 171, 581-584.

Weber, S., Lottspeich, F. \& Köhl, J. (1995). An epitope of elongation factor $\mathrm{Tu}$ is widely distributed within the bacterial and archaeal domains. J Bacteriol 175, 11-19.

Weijland, A. \& Parmeggiani, A. (1994). Why do two EF-Tu molecules act in the elongation cycle of protein biosynthesis? Trends Biochem Sci 19, 188-193.

Wenzig, P. \& Schleifer, K.-H. (1989). Unusually strong immunological cross-reaction between elongation factor Tu of Escherichia coli and Bacillus subtilis. Arch Microbiol 152, 258-262.

Received 22 December 1997; revised 25 March 1998; accepted 30 March 1998. 